\title{
Supplementation of diets with Brazil nut powder can meet dietary methionine requirement of organic broiler chickens
}

\author{
James C. Foutz • Marie C. Milfort • Alberta L. Fuller • \\ Woo K. Kim • Romdhane Rekaya • \\ Samuel E. Aggrey (D)
}

Received: 1 February 2019 /Accepted: 29 November 2019 /Published online: 3 January 2020

(C) The Author(s) 2020

\begin{abstract}
Synthetic amino acids are not permitted in organic feeds by the National Organic Standard Board (NOSB) in the USA. However, low levels of methionine (Met) are permitted, and the NOSB recommends $0.1 \%$ synthetic Met for broilers. Inadequate level of dietary methionine poses concerns pertaining to health and welfare of broilers, as these limitations lead to possible Met deficiency. This research examined the effects of complete replacement of synthetic DL-methionine (DLM) by Brazil nut powder in a $100 \%$ organic diet. Eight hundred Ross 308 chicks were hatched and randomly divided into 4 treatments with 4 replicates of 50 chicks and raised for 56 days. Treatments included birds fed a conventional diet and raised organically (Conv_Org), NOSB diet raised organically (NOSB_Org), 100\% organic diet and raised organically (Org_Org), and a conventional diet raised conventionally (Conv_Conv). Body weight at 56 days were 3960, 3995, 3981, and $3676 \mathrm{~g}$ for Conv_Org, NOSB_Org, Org_Org, and Conv_Conv, respectively. Body weights of the Conv_Conv group were lower $(P<0.05)$ than the other treatments. The FCR (0-8 weeks) of Org_Org treatment was lower $(P<0.05)$ than the NOSB diet.
\end{abstract}

J. C. Foutz - M. C. Milfort · A. L. Fuller - W. K. Kim •

S. E. Aggrey $(\square)$

Department of Poultry Science, University of Georgia, Athens,

GA 30602, USA

e-mail: saggrey@uga.edu

R. Rekaya

Department of Animal and Dairy Science, University of Georgia, Athens, GA 30602, USA
The birds on the NOSB diet had increased feed intake perhaps to compensate for the deficiency in Met. The NOSB diet may not sufficiently meet the requirement of broiler chickens even when raised with access to pasture. There were no differences in carcass yield and composition in any treatment. We conclude that Brazil nut powder is a viable substitute for DLM in organically raised broilers, as there were no differences in growth and carcass yield and improved FCR when compared to current NOSB recommended diet.

Keywords Methionine $\cdot$ Brazil nuts · Organic production Conventional production

\section{Introduction}

Amino acids (AA) are vital in poultry diets. Essential $\mathrm{AA}$, which cannot be synthesized in adequate amounts in birds, are provided to poultry through the diet (Jankowski et al. 2014). Methionine (Met) is the first limiting AA in a typical corn and soybean meal (SBM) diet and plays an important role in poultry metabolism (Demattê Filho et al. 2016; Tesseraud et al. 2011). Met, a sulfur-containing AA, is involved in over 100 methylation reactions including the production of metabolites (Fu et al. 2016).

Though Met is central to poultry metabolism, conventional corn and SBM do not provide adequate Met for poultry (Jacob 2013), and as a result, poultry diets are supplemented with synthetic Met (Jankowski et al. 2014). This is acceptable for conventionally raised 
poultry, but organically raised poultry are limited in the use of synthetic ingredients in the diet by the National Organic Standards Board (NOSB). Synthetic Met is restricted to $2 \mathrm{lb}$ per ton of feed for organic broilers feed (USDA 2012; Riddle 2013) in the USA. In Europe, synthetic ingredients are required to be completely removed from organically reared poultry feed (EU 2018). To provide Met to organic poultry, producers have turned to alternative organic sources of Met. Various studies (Burley et al. 2015; Jacob 2013) have identified multiple plant- and animal-based sources of Met, including Brazil nut meal, fish meal, sesame hulls, and corn gluten meal. Brazil nut meal contains about $3.35 \%$ Met, while fish meal contains about 2\% Met. However, fish meal often leads to an undesirable fishy taste of the chicken's meat. Organic sesame hulls and corn gluten meal also contain high amounts of Met. Neither are commercially available in the USA. In addition to synthetic ingredient restrictions, organic broiler production requires unrestricted pasture access. Ponte et al. (2008b) reports that broilers with pasture access have improved performance compared to those without pasture access. Conversely, Ipek and Sozcu (2017) observed decreased performance of broilers with pasture access compared to conventionally reared broilers, while Moyle et al. (2014) reported no growth differences between pasture and nonpasture raised broilers.

For this study, Brazil nut powder was selected as a source of Met for poultry diets because of high Met content and digestibility. The digestible Met and cysteine in the Brazil nut powder used in the current study were $3.36 \%$ and $1.05 \%$, respectively (Milfort et al. 2017). Brazil nut powder was attained in a large commercial quantity for the means of this research. This study directly compares a diet containing Brazil nut powder to both an NOSB and conventional diet. Conventional and organic environmental effects on growth and performance were also examined.

\section{Materials and methods}

A total of 800 Ross 308 broilers were randomly divided into 4 treatment groups of 4 replicates each with 50 birds. Slower growing broilers were not used in this instance because of limited availability and limited use in large-scale production. Birds were raised for 8 weeks. From days 1 to 14, the birds received a mash starter diet.
Grower (days 15 to 28) and finisher (days 28 to 56) diets were pelleted. Three diets were formulated for this study. The conventional poultry diet was formulated using nonorganic and synthetic ingredients. The NOSB diet was formulated using all organic ingredients and adhered to USDA National Organic Program criteria and contained only $0.1 \%$ DL-methionine (DLM). The organic diet of interest was formulated using Brazil nut powder as a source of Met and utilizing only organic ingredients. All diets were formulated as best to meet all nutritional requirements for Ross 308 broilers. Naturally, Met restriction allowed the NOSB diet to fall short of Met requirements. The starter, grower, and finisher diets of all treatments are presented in Tables 1, 2, and 3, respectively. Four treatments were created using these 3 diets and 2 husbandry locations: birds fed the conventional diet and raised in an organic environment (Conv_Org), birds fed the NOSB diet and raised in an organic environment (NOSB_Org), birds fed the organic Brazil nut powder diet and raised in an organic environment (Org_Org), and birds fed the conventional diet and raised in a conventional environment (Conv_Conv). Both organic and conventional husbandry environments were University of Georgia poultry research sites.

At hatch, 50 chicks were placed in $1.22 \mathrm{~m}$ by $1.83 \mathrm{~m}$ conventional pens with pinewood shavings to ensure proper brooding conditions were achieved. The birds were brooded for 14 days. Lighting and temperature management practices were in accordance with Ross 308 standards (Aviagen 2014). At 14 days of age, Conv_Org, NOSB_Org, and Org_Org treatments were moved to an organic setting that adhered to organic production guidelines. The pens at the organic setting were lined with pine shavings and measured $8.23 \mathrm{~m}$ by $2.44 \mathrm{~m}$, with pasture area measuring $13.41 \mathrm{~m}$ by $2.44 \mathrm{~m}$ (1.06 $\mathrm{m}^{2}$ per bird). The birds were given $24-\mathrm{h}$ access to pasture, along with ab libitum water and feed via nipple drinkers and feeders. No artificial light was used in the organic environment. Conv_Conv was left in a conventional environment with no access to pasture and pens measuring $7.32 \mathrm{~m}$ by $1.83 \mathrm{~m}\left(0.27 \mathrm{~m}^{2}\right.$ per bird $)$. Conv_Conv birds were provided light for $16 \mathrm{~h}$ a day and $\overline{a b}$ libitum water and feed via identical nipple drinkers and feeders. Temperature at the conventional environment was kept at $26.5^{\circ} \mathrm{C}$; temperatures in the organic environment varied due to daily weather variation. Weekly body weights (BW) were taken from hatch till day 56. Feed intake per pen was also measured 
Table 1 Nutrient composition for starter diet

\begin{tabular}{|c|c|c|c|c|}
\hline Ingredient & Conv_Org & NOSB_Org & Org_Org & Conv_Conv \\
\hline \multicolumn{5}{|l|}{ Treatments $^{\mathrm{a}}$} \\
\hline Corn $(\%)$ & 54.07 & 38.00 & 61.20 & 54.07 \\
\hline Soybean meal (\%) & 38.11 & 28.70 & 22.93 & 38.11 \\
\hline Soybean oil (\%) & 3.00 & 3.50 & 0.00 & 3.00 \\
\hline Sunflower meal (\%) & 0.00 & 22.05 & 0.00 & 0.00 \\
\hline Brazil nuts (\%) & 0.00 & 0.00 & 12.00 & 0.00 \\
\hline Limestone (\%) & 0.68 & 0.00 & 0.00 & 0.68 \\
\hline Defluor. phos. (\%) & 1.80 & 2.00 & 2.18 & 1.80 \\
\hline Sand $(\%)$ & 0.00 & 4.27 & 0.00 & 0.00 \\
\hline Common salt (\%) & 0.30 & 0.25 & 0.30 & 0.30 \\
\hline Vitamin premix $(\%)$ & 0.50 & 0.50 & 0.50 & 0.50 \\
\hline Mineral premix $(\%)$ & 0.08 & 0.08 & 0.08 & 0.08 \\
\hline DL-methionine $(\%)$ & 0.29 & 0.10 & 0.00 & 0.29 \\
\hline L-lysine $\mathrm{HCl}(\%)$ & 0.17 & 0.35 & 0.52 & 0.17 \\
\hline Threonine $(\%)$ & 0.99 & 0.20 & 0.29 & 0.99 \\
\hline \multicolumn{5}{|l|}{ Composition $^{\mathrm{b}}$} \\
\hline M.E. (Kcal/g) & 3.06 & 3.05 & 3.06 & 3.06 \\
\hline Protein $(\%)$ & 23.33 & 23.35 & 23.33 & 23.33 \\
\hline LYS (\%) & 1.28 & 1.27 & 1.28 & 1.28 \\
\hline $\operatorname{MET}(\%)$ & 0.62 & 0.43 & 0.63 & 0.62 \\
\hline CYS (\%) & 0.30 & 0.27 & 0.32 & 0.30 \\
\hline THR (\%) & 1.77 & 0.83 & 0.86 & 1.77 \\
\hline Calcium (\%) & 0.96 & 1.01 & 1.04 & 0.96 \\
\hline Avail. phos. (\%) & 0.48 & 0.48 & 0.48 & 0.48 \\
\hline
\end{tabular}

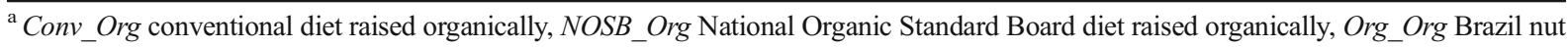
powder containing diet raised organically, Conv_Conv conventional diet raised organically

${ }^{\mathrm{b}}$ LYS lysine, MET methionine, CYS cysteine, THR threonine, Avail. phos. available phosphorus

weekly over the span of the experiment. On day 56,3 males and 3 females from each replicate were randomly selected and processed for carcass composition which comprised of carcass, Pectoralis (P.) major, P. minor, drum, thigh, and abdominal fat yield. Birds were killed by electrical stunning and exsanguination. The birds underwent soft scalding and de-feathering by plucking equipment. Evisceration and fat pad removal were done manually. Hot carcass weight and fat pad weight were then taken. All carcasses were immersion-chilled overnight. Carcasses were then weighed and manually separated into the breast, tenderloin, thigh, drum, and wing.

The following model was implemented using PROC GLM in SAS 9.4 (SAS 2017)

$Y_{i j}=\mu+T_{j}+e_{i j}$ where $Y_{i j}$ is the measurement for any given treatment for bird $i$ in treatment $j, \mu$ is the overall mean, $T_{j}$ is the effect of treatment $j$, and $e_{i j}$ is the random error term. The Tukey test evaluated statistical significance between treatments at $P<0.05$.

\section{Results}

The weekly BW of birds are presented in Table 4. At the end of the starter phase, Conv_Conv treatment birds were heavier $(P<0.05)$ than those fed the Org_Org or NOSB_Org diet. However, at the end of the grower phase, there was no difference between the Conv_Org, NOSB_Org, and Conv_Conv treatments. The birds in the Org_Org 
Table 2 Nutrient composition for grower diet

\begin{tabular}{|c|c|c|c|c|}
\hline Ingredient & Conv_Org & NOSB_Org & Org_Org & Conv_Conv \\
\hline \multicolumn{5}{|l|}{ Treatments $^{\mathrm{a}}$} \\
\hline Corn $(\%)$ & 58.22 & 42.75 & 64.73 & 58.22 \\
\hline Soybean meal (\%) & 34.20 & 25.00 & 20.75 & 34.20 \\
\hline Soybean oil (\%) & 3.00 & 3.50 & 0.25 & 3.00 \\
\hline Sunflower meal (\%) & 0.00 & 22.05 & 0.00 & 0.00 \\
\hline Brazil nuts (\%) & 0.00 & 0.00 & 10.75 & 0.00 \\
\hline Limestone (\%) & 0.68 & 0.00 & 0.00 & 0.68 \\
\hline Defluor. phos. (\%) & 1.60 & 1.80 & 1.95 & 1.60 \\
\hline Sand $(\%)$ & 0.00 & 3.27 & 0.00 & 0.00 \\
\hline Common salt (\%) & 0.30 & 0.30 & 0.25 & 0.30 \\
\hline Vitamin premix $(\%)$ & 0.50 & 0.50 & 0.50 & 0.50 \\
\hline Mineral premix (\%) & 0.08 & 0.08 & 0.08 & 0.08 \\
\hline DL-methionine $(\%)$ & 0.25 & 0.10 & 0.00 & 0.25 \\
\hline L-Lysine $\mathrm{HCl}(\%)$ & 0.17 & 0.35 & 0.45 & 0.17 \\
\hline Threonine (\%) & 0.99 & 0.30 & 0.29 & 0.99 \\
\hline \multicolumn{5}{|l|}{ Composition $^{\mathrm{b}}$} \\
\hline M.E. (Kcal/g) & 3.10 & 3.10 & 3.10 & 3.10 \\
\hline Protein $(\%)$ & 21.75 & 21.69 & 21.64 & 21.75 \\
\hline LYS (\%) & 1.18 & 1.18 & 1.16 & 1.18 \\
\hline MET (\%) & 0.56 & 0.41 & 0.58 & 0.56 \\
\hline CYS (\%) & 0.29 & 0.25 & 0.30 & 0.29 \\
\hline $\operatorname{THR}(\%)$ & 1.71 & 0.88 & 0.82 & 1.71 \\
\hline Calcium (\%) & 0.88 & 0.95 & 0.98 & 0.88 \\
\hline Avail. phos. (\%) & 0.44 & 0.44 & 0.44 & 0.44 \\
\hline
\end{tabular}

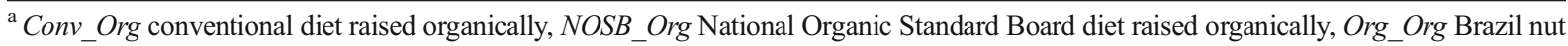
powder containing diet raised organically, Conv_Conv conventional diet raised organically

${ }^{\mathrm{b}}$ LYS lysine, MET methionine, CYS cysteine, THR threonine, Avail. phos. available phosphorus

treatment were significantly lighter $(P<0.05)$ than all other treatments. At the end of the finisher phase, all the birds raised in the organic environment were significantly heavier $(P<0.05)$ than those raised in the conventional environment. At day 56, there was no difference in BW among the Conv_Org, NOSB_Org, and Org_Org treatments. The body weight gain (BWG), feed conversion (FCR), and feed intake (FI) for the treatments at the three phases of growth are presented in Table 5 . At the end of the starter phase, the Conv_Conv treatment had higher BWG $(P<0.05)$ and lower FCR $(P<0.05)$ than the NOSB and Org_Org treatments. The NOSB_Org treatment had higher BWG $(P<0.05)$ and higher FI $(P<0.05)$ than the
Org_Org birds. At the end of the grower phase, the NOSB_Org birds gained more weight $(P<0.05)$ than the Org_Org and Conv_Conv treatment birds, but the Conv_Org birds had significantly better FCR $(P<0.05)$ than all the other treatments. At the end of the finisher phase, all the birds grown organically had significantly higher $(P<0.05)$ BWG than their counterparts raised in the conventional production environment. The Org_Org treatment had better FCR $(P<0.05)$ than the NOSB_Org and Conv_Conv treatment birds. There was no difference in FCR between the Org_Org and Conv_Org at the end of the finisher phase. From hatch till day 56, there were no differences in BWG among the treatments raised 
Table 3 Nutrient composition for finisher diet

\begin{tabular}{|c|c|c|c|c|}
\hline Ingredient & Conv_Org & NOSB_Org & Org_Org & Conv_Conv \\
\hline \multicolumn{5}{|l|}{ Treatments ${ }^{\mathrm{a}}$} \\
\hline Corn $(\%)$ & 61.88 & 42.00 & 66.00 & 61.88 \\
\hline Soybean meal (\%) & 29.90 & 21.25 & 18.00 & 29.90 \\
\hline Soybean oil (\%) & 3.85 & 5.25 & 2.00 & 3.85 \\
\hline Sunflower meal (\%) & 0.00 & 25.00 & 0.00 & 0.00 \\
\hline Brazil nuts (\%) & 0.00 & 0.00 & 10.50 & 0.00 \\
\hline Limestone (\%) & 0.65 & 0.00 & 0.00 & 0.65 \\
\hline Defluor. phos. (\%) & 1.45 & 1.60 & 1.95 & 1.45 \\
\hline Sand $(\%)$ & 0.00 & 3.27 & 0.00 & 0.00 \\
\hline Common salt (\%) & 0.27 & 0.30 & 0.25 & 0.27 \\
\hline Vitamin premix $(\%)$ & 0.50 & 0.50 & 0.50 & 0.50 \\
\hline Mineral premix (\%) & 0.08 & 0.08 & 0.08 & 0.08 \\
\hline DL-methionine (\%) & 0.25 & 0.10 & 0.00 & 0.25 \\
\hline L-lysine $\mathrm{HCl}(\%)$ & 0.17 & 0.35 & 0.43 & 0.17 \\
\hline Threonine (\%) & 1.00 & 0.30 & 0.29 & 1.00 \\
\hline \multicolumn{5}{|l|}{ Composition $^{\mathrm{b}}$} \\
\hline M.E. (Kcal/g) & 3.20 & 3.20 & 3.20 & 3.20 \\
\hline Protein $(\%)$ & 19.97 & 20.22 & 20.07 & 19.97 \\
\hline LYS (\%) & 1.07 & 1.09 & 1.07 & 1.07 \\
\hline $\operatorname{MET}(\%)$ & 0.54 & 0.40 & 0.56 & 0.54 \\
\hline CYS (\%) & 0.27 & 0.24 & 0.28 & 0.27 \\
\hline $\operatorname{THR}(\%)$ & 1.66 & 0.84 & 0.78 & 1.66 \\
\hline Calcium (\%) & 0.81 & 0.89 & 0.97 & 0.81 \\
\hline Avail. phos. (\%) & 0.41 & 0.41 & 0.43 & 0.41 \\
\hline
\end{tabular}

${ }^{a}$ Conv_Org conventional diet raised organically, NOSB_Org National Organic Standard Board diet raised organically, Org_Org Brazil nut powder containing diet raised organically, Conv_Conv conventional diet raised organically

${ }^{\mathrm{b}}$ LYS lysine, MET methionine, CYS cysteine, THR threonine, Avail. phos. available phosphorus

under organic environment; however, all the organically raised treatments had higher BWG $(P<0.05)$ than their Conv_Conv counterparts. The Org_Org and Conv_Org treatment birds had better FCR $(P<0.05)$ than the NOSB_Org birds.

When comparing only birds fed a conventional diet raised either organically or conventionally, Conv_Org treatment birds had a significantly higher $(P<0.05) \mathrm{BW}$ at day 56 compared to Conv_Conv treatment birds. Prior to husbandry environment placement (day 14), Conv_Org and Conv_Conv treatment birds' BW did not significantly differ $(P>0.05)$. On day 21, Conv_Conv treatment birds had significantly higher $(P<0.05)$ BW than Conv_Org treatment birds. However, BW did not significantly differ $(P>0.05)$ between Conv_Org and Conv_Conv treatment birds on day 28 . Conv_Org treatment birds had a significantly higher $(P<0.05)$ BW compared to Conv_Conv treatment birds on day 35 , day 42 , day 49 , and day 56 .

The carcass composition yields among all treatments are provided in Table 6 . There were no differences $(P>0.05)$ in carcass, $P$. major, $P$. minor, abdominal fat, drum, and thigh yields among all the treatments.

Bird mortalities for the 4 treatments during the entire 8-week trial were $7.5,6.5,10.0$, and $5.0 \%$ for Conv_Org, NOSB_Org, Org_Org, and Conv_Conv treatments, respectively. Though percent mortality appears to differ, there was no significant difference $(P>0.05)$ in mortality between the four treatments. 
Table 4 Weekly body weights ( $\mathrm{g}$ ) of chickens raised under organic or conventional environment and fed organic, NOSB or conventional diet

\begin{tabular}{|c|c|c|c|c|c|c|c|}
\hline Phase & Age & Conv_Org $(N=163)$ & NOSB_Org $(N=166)$ & Org_Org $(N=158)$ & Conv_Conv $(N=176)$ & SEM & $\operatorname{Pr}>F$ \\
\hline \multicolumn{8}{|c|}{ Treatments $^{\mathrm{d}}$} \\
\hline \multirow[t]{3}{*}{ Starter } & 0 & $42.53^{\mathrm{ab}}$ & $43.18^{\mathrm{a}}$ & $42.23^{\mathrm{b}}$ & $42.18^{\mathrm{b}}$ & 0.09 & 0.0300 \\
\hline & 7 & $156.09^{\mathrm{ab}}$ & $156.19^{\mathrm{ab}}$ & $151.27^{\mathrm{b}}$ & $161.05^{\mathrm{a}}$ & 0.61 & $<0.0001$ \\
\hline & 14 & $430.86^{\mathrm{ab}}$ & $420.87^{\mathrm{b}}$ & $386.98^{\mathrm{c}}$ & $435.71^{\mathrm{a}}$ & 1.89 & $<0.0001$ \\
\hline \multirow[t]{2}{*}{ Grower } & 21 & $823.39^{b}$ & $816.47^{\mathrm{b}}$ & $755.13^{\mathrm{c}}$ & $900.28^{\mathrm{a}}$ & 3.86 & $<0.0001$ \\
\hline & 28 & $1447.34^{\mathrm{a}}$ & $1446.28^{\mathrm{a}}$ & $1364.73^{\mathrm{b}}$ & $1419.16^{\mathrm{a}}$ & 6.10 & $<0.0001$ \\
\hline \multirow[t]{4}{*}{ Finisher } & 35 & $2214.94^{\mathrm{a}}$ & $2220.52^{\mathrm{a}}$ & $2117.69^{\mathrm{b}}$ & $2087.11^{\mathrm{b}}$ & 9.39 & $<0.0001$ \\
\hline & 42 & $2742.69^{\mathrm{a}}$ & $2759.33^{\mathrm{a}}$ & $2670.87^{\mathrm{ab}}$ & $2623.44^{\mathrm{b}}$ & 11.58 & $<0.0001$ \\
\hline & 49 & $3333.71^{\mathrm{a}}$ & $3361.26^{\mathrm{a}}$ & $3252.61^{\mathrm{ab}}$ & $3196.14^{\mathrm{b}}$ & 14.31 & $<0.0001$ \\
\hline & 56 & $3960.08^{\mathrm{a}}$ & $3996.36^{\mathrm{a}}$ & $3984.58^{\mathrm{a}}$ & $3677.55^{\mathrm{b}}$ & 18.02 & $<0.0001$ \\
\hline
\end{tabular}

${ }^{\mathrm{a}-\mathrm{c}}$ Means within the same row with no common superscript differ significantly $(P \leq 0.05)$

${ }^{\mathrm{d} C}$ Conv_Org conventional diet raised organically, NOSB_Org National Organic Standard Board diet raised organically, Org_Org Brazil nut powder containing diet raised organically, Conv_Conv conventional diet raised organically

Table 5 Mean BWG $(\mathrm{g})$, feed intake $(\mathrm{g})$, and FCR of treatments for all phases ${ }^{\mathrm{d}}$

\begin{tabular}{|c|c|c|c|c|c|c|}
\hline & $\begin{array}{l}\text { Conv_Org } \\
(\mathrm{N}=163)\end{array}$ & $\begin{array}{l}\text { NOSB_Org } \\
(\mathrm{N}=1 \overline{66})\end{array}$ & $\begin{array}{l}\text { Org_Org } \\
(\mathrm{N}=158)\end{array}$ & $\begin{array}{l}\text { Conv_Conv } \\
(\mathrm{N}=176)\end{array}$ & SEM & $\operatorname{Pr}>\mathrm{F}$ \\
\hline \multicolumn{7}{|c|}{ Treatments $^{\mathrm{e}}$} \\
\hline \multicolumn{7}{|c|}{ Starter phase (0-14 days) } \\
\hline $\begin{array}{c}\text { BWG } \\
(\mathrm{g})\end{array}$ & $388.35^{\mathrm{ab}}$ & $378.03^{\mathrm{b}}$ & $345.08^{\mathrm{c}}$ & $393.34^{\mathrm{a}}$ & 7.10 & $<0.0001$ \\
\hline FI (g) & $465.86^{\mathrm{b}}$ & $510.26^{\mathrm{a}}$ & $465.57^{\mathrm{b}}$ & $467.88^{\mathrm{b}}$ & 6.70 & $<0.0001$ \\
\hline FCR & $1.20^{\mathrm{b}}$ & $1.35^{\mathrm{a}}$ & $1.34^{\mathrm{a}}$ & $1.19^{\mathrm{b}}$ & 0.02 & $<0.0001$ \\
\hline \multicolumn{7}{|c|}{ Grower phase (15-28 days) } \\
\hline $\begin{array}{l}\text { BWG } \\
(\mathrm{g})\end{array}$ & $1016.66^{\mathrm{ab}}$ & $1025.19^{a}$ & $976.49^{b}$ & $983.78^{b}$ & 12.72 & 0.0028 \\
\hline $\mathrm{FI}(\mathrm{g})$ & $1461.72^{\mathrm{b}}$ & $1600.84^{\mathrm{a}}$ & $1541.96^{\mathrm{b}}$ & $1503.66^{\mathrm{b}}$ & 26.85 & $<0.0001$ \\
\hline FCR & $1.44^{\mathrm{b}}$ & $1.56^{\mathrm{a}}$ & $1.58^{\mathrm{a}}$ & $1.52^{\mathrm{a}}$ & 0.02 & $<0.0001$ \\
\hline \multicolumn{7}{|c|}{ Finisher phase (29-56 days) } \\
\hline $\begin{array}{c}\text { BWG } \\
(\mathrm{g})\end{array}$ & $2546.06^{\mathrm{a}}$ & $2549.39^{\mathrm{a}}$ & $2618.10^{\mathrm{a}}$ & $2257.45^{\mathrm{b}}$ & 67.27 & $<0.0001$ \\
\hline $\mathrm{FI}(\mathrm{g})$ & $5038.18^{\mathrm{ab}}$ & $5285.01^{\mathrm{a}}$ & $4924.95^{\mathrm{ab}}$ & $4671.23^{\mathrm{b}}$ & 94.47 & $<0.0001$ \\
\hline FCR & $1.98^{\mathrm{ab}}$ & $2.07^{\mathrm{a}}$ & $1.88^{\mathrm{b}}$ & $2.07^{\mathrm{a}}$ & 0.04 & $<0.0001$ \\
\hline \multicolumn{7}{|c|}{ Cumulative ( $0-56$ days) } \\
\hline $\begin{array}{l}\text { BWG } \\
(\mathrm{g})\end{array}$ & $3951.06^{\mathrm{a}}$ & $3952.62^{\mathrm{a}}$ & $3939.67^{\mathrm{a}}$ & $3634.56^{\mathrm{b}}$ & 66.03 & $<0.0001$ \\
\hline FI (g) & $6965.75^{\mathrm{b}}$ & $7396.10^{\mathrm{a}}$ & $6932.49^{\mathrm{b}}$ & $6642.77^{\mathrm{b}}$ & 91.85 & $<0.0001$ \\
\hline FCR & $1.76^{\mathrm{b}}$ & $1.87^{\mathrm{a}}$ & $1.76^{\mathrm{b}}$ & $1.82^{\mathrm{ab}}$ & 0.02 & $<0.0001$ \\
\hline
\end{tabular}

${ }^{\mathrm{a}-\mathrm{c}}$ Means within the same row with no common superscript differ significantly $(P \leq 0.05)$

${ }^{\mathrm{d}} B W G$ body weight gain, $F I$ feed intake, $F R C$ feed conversion ratio

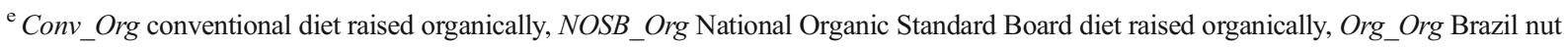
powder containing diet raised organically, Conv_Conv conventional diet raised organically 
Table 6 Mean carcass composition (\%) of treatments

\begin{tabular}{|c|c|c|c|c|c|c|}
\hline Composition (\%) & $\begin{array}{l}\text { Conv_Org } \\
(\mathrm{N}=24)\end{array}$ & $\begin{array}{l}\text { NOSB_Org } \\
(\mathrm{N}=2 \overline{4})\end{array}$ & Org_Org $(\mathrm{N}=24)$ & $\begin{array}{l}\text { Conv_Conv } \\
(N=24)\end{array}$ & SEM & $\operatorname{Pr}>F$ \\
\hline \multicolumn{7}{|l|}{ Treatments $^{\mathrm{a}}$} \\
\hline Carcass & 74.68 & 74.16 & 74.11 & 74.85 & 0.45 & 0.1995 \\
\hline Fat Pad & 2.23 & 2.35 & 2.14 & 2.19 & 0.17 & 0.7395 \\
\hline P. major & 25.00 & 25.52 & 25.93 & 27.01 & 0.58 & 0.2597 \\
\hline P. minor & 6.26 & 5.24 & 4.93 & 5.58 & 0.48 & 0.1245 \\
\hline Wings & 10.11 & 10.67 & 10.09 & 10.54 & 0.17 & 0.2443 \\
\hline Drums & 13.30 & 13.57 & 13.92 & 13.02 & 0.20 & 0.1497 \\
\hline Thighs & 17.57 & 17.97 & 17.49 & 17.28 & 0.30 & 0.7519 \\
\hline
\end{tabular}

$\overline{{ }^{a} \text { Conv_Org conventional diet raised organically, NOSB_Org National Organic Standard Board diet raised organically, Org_Org Brazil nut }}$ powder containing diet raised organically, Conv_Conv conventional diet raised organically

\section{Discussion}

This study focuses on growth and performance comparisons between broilers fed organically sourced Met and broilers fed conventional synthetic Met. Overall, broiler chickens fed a diet that included Brazil nut powder and raised organically showed a more desirable cumulative FCR and lower feed intake than chickens fed a standard NOSB diet containing synthetic Met and raised organically. Additionally, there was no difference in final BW or cumulative FCR between Org_Org and Conv_Org, demonstrating Brazil nut powder as a viable inclusion for organic broiler diets.

Burley (2012) fed a diet that contained Brazil nut protein powder and wheat middlings to broilers raised in battery cages. The starter and grower diets contained 5.50 and $4.26 \%$ Brazil nut protein powder, respectively, and met the Met requirement for the Ross 308 broiler chickens used. The study concluded that over the duration of the trial, broiler chickens fed Brazil nut protein powder had comparable growth, feed intake, and FCR with their counterparts fed a conventional balanced diet.

In the current study, broiler chicken diets that included Brazil nut powder were able to meet the Met requirement. At the starter phase, all the birds were raised in a conventional production environment; therefore, the Conv_Conv and Conv_Org treatment birds were expected to grow faster than the NOSB_Org birds, since the conventional diet met the Met requirement of the birds and the NOSB diets contained less than required Met. The chickens fed the NOSB diet in the starter phase consumed more feed than their counterparts, possibly to compensate for the deficient Met diet. The Org_Org treatment had comparable feed intake with the Conv_Conv group in the starter phase, yet the birds had significantly lower growth. It is possible that there are unknown nutritional elements in Brazil nut powder that have a negative effect on chicks. A possible anti-nutritional element could be a high amount of conjugated linoleic acid. Szymczyk et al. (2001) saw decreased broiler body weight when fed an increased amount of conjugated linoleic acid. Brazil nuts are high in lipid content. Of those lipids, $40 \%$ is linoleic acid (USDA 2015).

At the end of the starter phase, 3 treatments were transferred to an organic environment where they had access to pasture. At the end of the grower phase (day 28), the Conv_Org, NOSB_Org, and Conv_Conv treatments had similar BW, but the BW for the Org_Org treatment group was significantly lower. Pasturing may have played a role in the growth of the chickens on the NOSB diet. Even though the absolute BW of the Org_Org treatment group was lower than all other treatments, their gain during the grower phase was similar to that of the Conv_Conv and the Conv_Org groups but remained lower than the NOSB_Org group. Chickens in the NOSB_Org treatment group still had a significantly increased feed intake in the grower phase compared to all other groups. At the end of the grower phase, the Conv_Org group had a better FCR than all the other 
groups. Pasture is a reservoir of nutrients from the vegetation present, and Ponte et al. (2008b) showed that pasture provides high amounts of protein to foraging broilers. Broiler chickens with access to pasture showed higher growth than their counterparts with no access to pasture. Additionally, broiler chickens have been shown to consume high amounts of pasture when fed a conventional corn-SBM diet (Ponte et al. 2008a, b). Moritz et al. (2005) explains with access to pasture comes increased access to nutrients, allowing pasture raised broilers to increase nutrient intake compared to nonpasture raised broilers, improving performance. Quantifying pasture intake was not of focus in this study; however it was observed that all organically raised treatments had steady pasture activity during dawn and dusk, with no one treatment standing out from the rest.

At the end of the finisher phase, all the birds raised in the organic production environment showed no difference in either BW or BWG. Chickens raised in the conventional environment had BW and gain that were significantly different from pasture-reared birds. At the finisher phase, the chickens on the NOSB diet still had a slightly increased feed intake compared to their other counterparts raised in the organic environment, but this increase was not significant. Conv_Conv chickens had significantly lower feed intake than the NOSB chickens and numerically lower feed intake compared to Conv_Org. The higher feed intake of the Conv_Org birds may be due to the forgiving temperatures of dawn and dusk, when temperature is relatively low, allowing for more activity and feeding.

In the current study, it appears that birds that had access to pasture showed increased growth when compared to their counterparts in the conventional environment. This is in accordance with the observation of Ponte et al. (2008a, b). However, Fanatico et al. (2009) and Moyle et al. (2014) reported no differences in BWG, feed intake, and FCR of fast-growing broilers provided access or no access to pasture. Moyle et al. (2014) postulated that the lack of performance difference may be due to limited available nutrients present within the forage. In the current study, forage was not analyzed for nutrient availability. Recently, Ipek and Sozcu (2017) reported that slow-growing broiler chickens with access to pasture had lower final BW and FCR (days 42-84) than their counterparts raised in a conventional environment. Possible reasons for this outcome include limited nutrient availability of forage and more exercise and activity from broilers with access to pasture. In the current study, we did not monitor the activity of birds or the amount of time they spent outdoors on pasture; however, the relationship between access to pasture and different broiler chicken strains (slow, medium, and fast growth) requires further investigation.

It has been reported that Brazil nut has high levels of selenium compared to other feed ingredients (NIH 2016). We did not analyze the diet for selenium. However, there are studies that suggest dietary selenium levels could affect performance. Choct et al. (2004) reported that male broilers receiving $0.1 \mathrm{mg} / \mathrm{kg}$ of selenium consumed more feed than their counterparts that received $0.25 \mathrm{mg} / \mathrm{kg}$ of selenium. In that study, there were no differences in BW, but those on the $0.25 \mathrm{mg} / \mathrm{kg}$ of selenium had an improved FCR compared to those on the $0.1 \mathrm{mg} / \mathrm{kg}$. Besides high amounts of sulfur amino acids in Brazil nut (Milfort et al. 2017), high levels of selenium may reflect the favorable cumulative FCR of the chickens in the Org_Org treatment.

The dietary treatment and production environment did not affect the carcass yield and carcass composition. Fanatico et al. (2009) and Moyle et al. (2014) also reported similar results in fast-growing broilers with or without access to pasture. However, in slow-growing broiler chickens, Ipek and Sozcu (2017) reported that chickens with access to pasture had lower breast and abdominal fat yields compared to their counterparts raised conventionally with no access to pasture. The current study focused on the utility of Brazil nut as a substitute for synthetic Met in different phases of organic broiler chicken feed. Future studies need to include cost optimization of the diet and the use of a wider array of organic ingredients for improving growth and performance of organically raised broilers.

\section{Conclusion}

As a proof of principle, the current study has demonstrated that it is possible to formulate an organic broiler chicken diet without synthetic Met supplementation. The tolerance of the chickens to an organic diet with Brazil nut powder may be an issue for young birds and needs to be investigated further. It is also apparent that even in an organic production environment, the NOSB diet is deficient in Met and may not meet the needs of broiler chickens. Also, fast-growing broilers perform better in an organic production environment with access to pasture than their counterparts without access to pasture. Carcass yield is similar in fast-growing 
chickens with or without access to pasture. Future studies should monitor activity and time spent on pasture in order to evaluate the relationship between foraging behavior, activity, and performance.

Acknowledgments This research was supported by funds from USDA Organic Transition Grant 2014-51106-22093. The Ross 308 eggs were donated by CWT Farms, Gainesville, GA.

Open Access This article is licensed under a Creative Commons Attribution 4.0 International License, which permits use, sharing, adaptation, distribution and reproduction in any medium or format, as long as you give appropriate credit to the original author(s) and the source, provide a link to the Creative Commons licence, and indicate if changes were made. The images or other third party material in this article are included in the article's Creative Commons licence, unless indicated otherwise in a credit line to the material. If material is not included in the article's Creative Commons licence and your intended use is not permitted by statutory regulation or exceeds the permitted use, you will need to obtain permission directly from the copyright holder. To view a copy of this licence, visit http://creativecommons.org/licenses/by/4.0/.

\section{References}

Aviagen (2014) Ross Broiler Management Handbook. http://en. aviagen.com/assets/Tech_Center/Ross_Broiler/Ross-BroilerHandbook-2014i-EN.pdf

Burley HK (2012) Enrichment of methionine from naturally concentrated feedstuffs for use in organic poultry diets. Dissertation, The Pennsylvania State University

Burley HK, Patterson PH, Anderson KE (2015) Alternative ingredients for providing adequate methionine in organic poultry diets in the United States with limited synthetic amino acid use. Worlds Poult Sci J 71:493-504. https://doi.org/10.1017 /s0043933915002196

Choct M, Reinke N, Naylor AJ (2004) Selenium supplementation affects broiler growth performance, meat yield and feather coverage. Br Poult Sci 45:677-683

Demattê Filho L, Pereira D, Pereira G, Beutner C (2016) Effect of an unusual source of methionine on the performance of organic chickens. Organic Agriculture 6:191-197

EU (2018) Regulation (EU) 2018/848 Official Journal of the European Union

Fanatico AC, Owens CM, Emmert JL (2009) Organic poultry production in the United States: broilers. J Appl Poult Res 18:355-366

Fu Q, Leng ZX, Ding LR, Wang T, Wen C, Zhou YM (2016) Complete replacement of supplemental DL-methionine by betaine affects meat quality and amino acid contents in broilers. Anim Feed Sci Technol 212:63-69
Ipek A, Sozcu A (2017) The effects of access to pasture on growth performance, behavioural patterns, some blood parameters and carcass yield of a slow-growing broiler genotype. J Appl Anim Res 45:464

Jacob J (2013) Synthetic methionine and organic poultry diets. http://articles.extension.org/pages/69042/syntheticmethionine-and-organic-poultry-diets. Accessed Feb. 2018

Jankowski J, Kubińska M, Zduńczyk Z (2014) Nutritional and immunomodulatory function of methionine in poultry diets a review. Ann Anim Sci 14. https://doi.org/10.2478/aoas2013-0081

Milfort MC, Foutz J, Dunkley C, Davis AJ, Rekaya R, Aggrey SE (2017) Amino acid composition and digestibility of organic feed ingredients. Poult Sci 95

Moritz JS, Parsons AS, Buchanan NP, Baker NJ, Jaczynski J, Gekara OJ, Bryan WB (2005) Synthetic methionine and feed rRestriction effects on performance and meat quality of organically reared broiler chickens. J Appl Poult Res 14:521535

Moyle JR et al (2014) Growth performance of fast-growing broilers reared under different types of production systems with outdoor access: implications for organic and alternative production systems. J Appl Poult Res 23:212-220

NIH (2016) Selenium: dietary supplement fact sheet. https://ods. od.nih.gov/factsheets/Selenium-HealthProfessional/. Accessed Feb. 2018

Ponte PI et al (2008a) Restricting the intake of a cereal-based feed in free-range-pastured poultry: effects on performance and meat quality. Poult Sci 87:2032-2042. https://doi. org/10.3382/ps.2007-00522

Ponte PI et al (2008b) Pasture intake improves the performance and meat sensory attributes of free-range broilers. Poult Sci 87:71-79. https://doi.org/10.3382/ps.2007-00147

Riddle J (2013) Requirements for organic poultry production. https://eorganic.org/node/7959\#.VC1 ofvldUXE10.3382 /ps/peu055.html. Accessed August 2019

SAS (2017) SAS/SAT user guide: Statistics, 9.4 edn., Cary, NC: SAS Institute

Szymczyk B, Pisulewski PM, Szczurek W, Hanczakowski P (2001) Effects of conjugated linoleic acid on growth performance, feed conversion efficiency, and subsequent carcass quality in broiler chickens. Br J Nutr 85:465-473

Tesseraud S, Everaert N, Boussaid-Om Ezzine S, Collin A, Métayer-Coustard S, Berri C (2011) Manipulating tissue metabolism by amino acids. Worlds Poult Sci J 67:243252. https://doi.org/10.1017/s0043933911000274

USDA (2012) National organic program; amendment to the national list of allowed and prohibited substances (livestock) vol Federal Register

USDA (2015) National Nutrient Database for standard reference

Publisher's note Springer Nature remains neutral with regard to jurisdictional claims in published maps and institutional affiliations. 